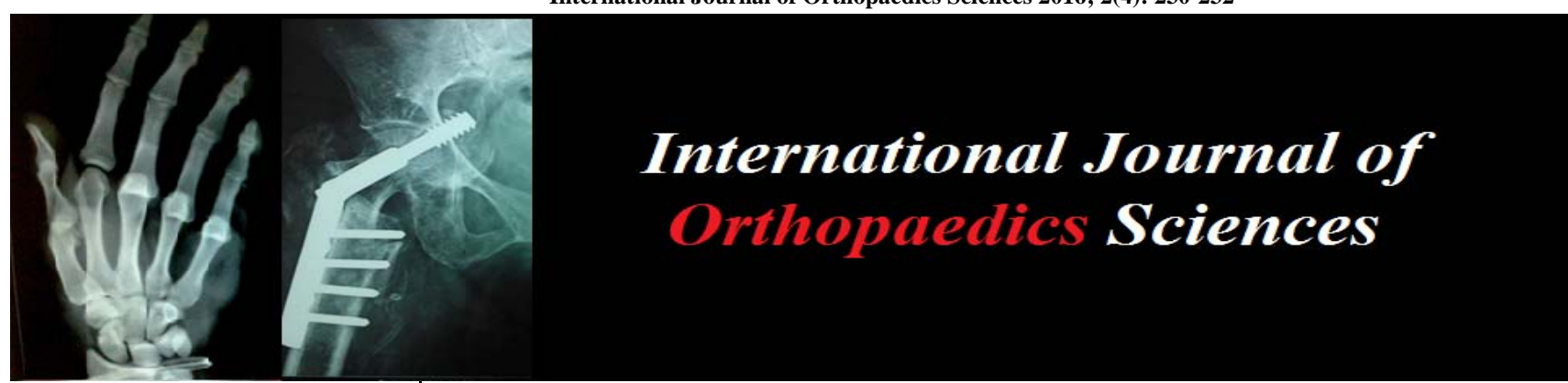

ISSN: 2395-1958

IJOS 2016; 2(4): 230-232

(C) 2016 IJOS

www.orthopaper.com

Received: 07-08-2016

Accepted: 08-09-2016

Vinod Kumar

M.S. (Ortho), Professor,

Department of Orthopaedics,

Maulana Azad Medical College

and Lok Nayak Hospital,

New Delhi, India

Narendran P

M.S. (Ortho), Senior Resident, Department of Orthopaedics,

Maulana Azad Medical College and Lok Nayak Hospital,

New Delhi, India

Deepak Kumar

Post Graduate Resident,

Department of Orthopaedics,

Maulana Azad Medical College

and Lok Nayak Hospital,

New Delhi, India

Ritika Walia

M.D. (Pathology), Assistant

Professor, Maulana Azad Medical

College, New Delhi, India
Correspondence

Narendran $P$

M.S. (Ortho), Senior Resident, Department of Orthopaedics,

Maulana Azad Medical College and Lok Nayak Hospital, New Delhi, India

\section{Avascular necrosis of femoral head presenting as pathological subcapital neck of femur fracture: An unclassified presentation}

\author{
Vinod Kumar, Narendran P, Deepak Kumar and Ritika Walia
}

DOI: $\underline{\text { http://dx.doi.org/10.22271/ortho.2016.v2.i4d.37 }}$

Abstract

Avascular necrosis of femoral head is not an uncommon chronic disorder of hip in adults. The patient presents to the health facility with varied range of symptoms based on the degree of collapse of the head and arthritic changes at hip. Avascular necrosis of hip presenting as subacute condition with pathological sub capital neck of femur fracture has not yet been reported. The commonly used Ficat and Arlet, university of Pennsylvania, association research circulation osseous and the Japanese Investigation Committee on Osteonecrosis do not include such a presentation in the classification nor is management. We report this in an Indian patient aged 42 , tailor by occupation presenting with pain and worsening of limp following a squatting event. MRI revealed avascular changes on both hips and sub capital neck of femur fracture on the left. We managed him with an uncemented total hip arthroplasty. The other side was managed conservatively as he was asymptomatic. He had a good result with a Harris hip score of 97 at $7^{\text {th }}$ month follow up.

Keywords: Avascular necrosis of hip, atypical presentation, pathological fracture, total hip replacement, Harris hip score

\section{Introduction}

Avascular or necrosis of the femoral heads (ONFH) in adults is not an uncommon condition caused by various etiologies and idiopathic in about $30 \%$ of cases ${ }^{[1]}$. It's a progressive debilitating condition with varied clinical presentation like painless hip, painful restriction of motion, shortening and deformities to total ankylosis ${ }^{[2]}$. The natural course of the disease is resorption bone formation, collapse, loss of articular contour, and arthritic changes of hip and ankylosis ${ }^{[3]}$. Osteonecrosis of femoral head presenting with a pathological fracture is less likely and unreported. We report this rare and atypical presentation in an Indian patient having ONFH presenting with sub capital femoral neck fracture. This atypical presentation has not been classified in the commonly used classifications. Hence, we report this rare presentation and its management.

\section{Case report}

A $42 \mathrm{yr}$ male, moderately built tailor, presented to the orthopedic OPD with sudden increase in pain and inability to use the left hip for about 5 days. He had chronic pain in the left hip and gluteal region associated with progressive limp for one half years. He was investigated and diagnosed to have ONFH on the left hip for which he refused to take any further treatment. He attributed the worsening of symptoms following a squatting event and required assistance to get up and walk thereafter. He was an alcoholic and tobacco chewer for 15 years. He denied any history of bleeding diathesis, trauma, infectious history, steroid intake or family history. Limb was in the attitude of flexion, adduction and external rotation. Clinical examination revealed tenderness in the left hip, thigh and gluteal wasting, proximally migrated trochanter, flexion and adduction deformities. His measurements revealed true shortening of $1 \mathrm{~cm}$, painful hip movements with 50 degree and 10 degree arc of motion in sagittal and coronal plane respectively. Rotatory movements were also painful with telescoping. His right hip was asymptomatic and normal. Harris hip score was 42. 
Prior plain radiographs showed increased sclerosis and lytic lesions in the left hip, features suggestive of ONFH. Plain radiograph of the left hip subsequent to inability to walk revealed increased sclerosis with well-maintained joint space and contour but with subcapital femoral neck fracture. MRI of both hips revealed osteonecrosis involving both heads and pathological subcapital fracture on the left side.

We had difficulty in classifying or staging the avascular femoral head changes because the presentation of ONFH with sub capital fracture has not been included in the commonly used classifications. Having discussed the treatment options with the patient, we had planned for a left total hip arthroplasty since the patient wanted an early, stable and mobile hip. The contour of the head was preserved and the fracture margins were irregular and showed no capacity to bleed. We did an uncemented total hip arthroplasty. The histopathology of the femoral head and neck showed gross necrosis in the marrow and lipid infiltration features consistent with osteonecrosis of femoral head. Post op period was uneventful and rehabilitation was per protocol. The other hip was managed conservatively as he was asymptomatic and had incidental changes on MRI. His Harris hip score at 6 months post-operative was 97 .

\section{Discussion}

Avascular Osteonecrosis of the femoral head in adult is one of the common debilitating conditions of the hip. It has various etiologies (table 1) but in $30 \%$ of cases the etiology is uncertain. It shows $\mathrm{b} / 1$ involvement in about $55 \%$ cases ${ }^{[1]}$. The pathological changes taking place after the vascular insult are remodeling, subchondral fractures causing collapse, loss of contour of head and arthritic changes [3]. The clinical presentation depends on the stage of disease between painless mobile hip to arthritic and ankylosed hip ${ }^{[4]}$. our patient had $b / 1$ hip involvement and presented with pathological subcapital fracture in left hip and asymptomatic right hip. Our patient fulfilled the criteria for the diagnosis of idiopathic ONFH (table 2) ${ }^{[5]}$. To our knowledge, ONFH presenting with subcapital fracture has not been reported.

The are many classifications/staging systems used for ONFH based on X-ray, MRI and bone scan like Ficat and Arlet ${ }^{[4]}$, university of Pennsylvania [6], association research circulation osseous (ASRO) ${ }^{[7]}$, marcus et al. ${ }^{[8]}$. And the Japanese Investigation Committee on Osteonecrosis ${ }^{[9]}$. Ficat and Arlet (table 3 ) is the most commonly preferred. It is clear that the classification does not include ONFH presenting with pathological neck of femur fractures.

There are various non operative treatment options like Extracorporeal shock wave therapy, Hyperbaric oxygen and operative methods like core decompression, stem cells implantation, vascularized and Non-vascularized bone graft, muscle pedicle bone graft, proximal femoral osteotomy and arthroplasty used alone or in combination for various stages of avn ${ }^{[10]}$.

However, treatment options have not been discussed for the presentation with pathological fractures. Arthroplasty appeared to be the best option as per the patient requirements. Hence we did an uncemented total hip system for this patient.

\section{Conclusion}

Avascular necrosis of femoral head presenting with pathological fractures is a rare entity and not included in the common classifications. Patients have good outcomes with total hip replacement.

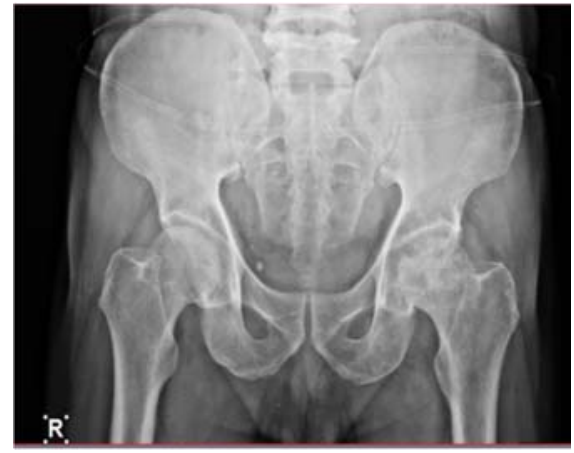

Fig 1: initial plain radiograph showing sclerosis and lytic lesions. Maintained joint space and contour is also noted.

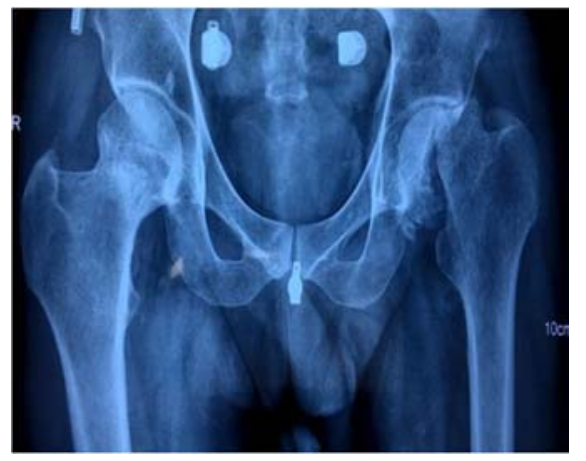

Fig 2: X-ray of both hips- avn changes in head and part of neck. Contour of head is normal and maintained joint space. Subcapital fracture is also seen. Not classified in the Ficat and Arlet staging

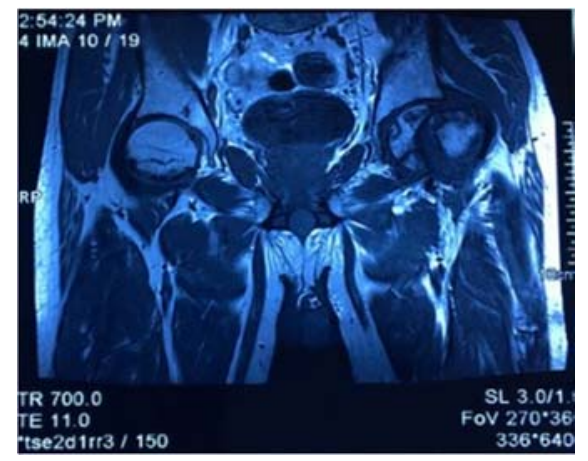

Fig 3: T1 spin echo - serpiginous hypo intense line of low signal in coronal section- classical of ONFH.

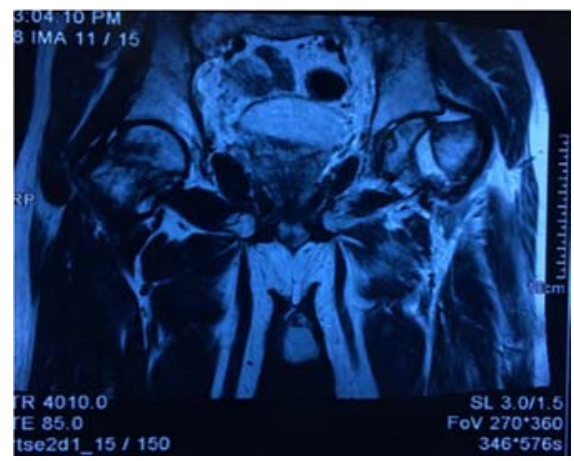

Fig 4: T2 spin -double line sign and joint effusion is seen. Edema noted in both sides of fracture. Necrotic features present in right hip also. 


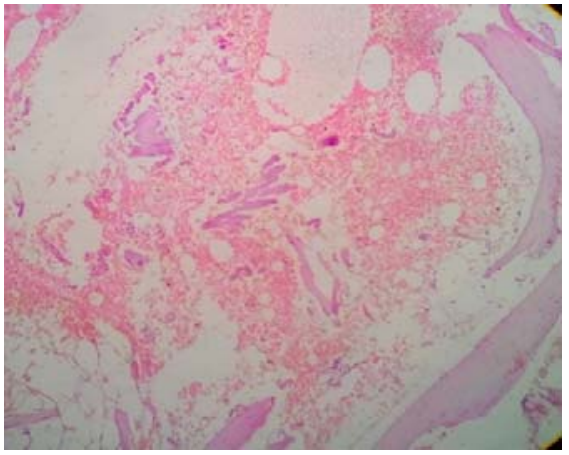

Fig 5: Description - Viable trabecular bone at the periphery with spicules of necrosed acellular bone at the centre. H\&E, 100X

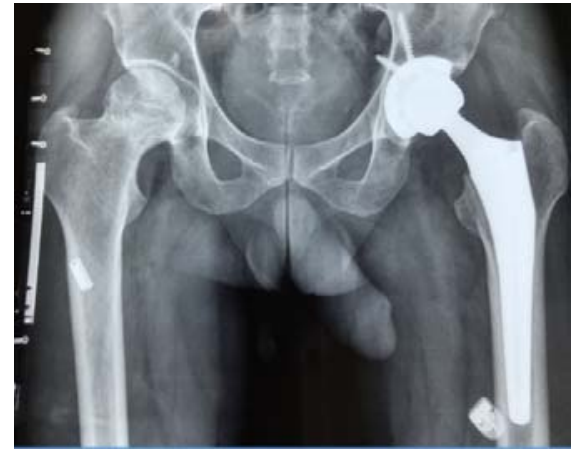

Fig 6: Uncemented total hip arthroplasty was done on the left side.

Table 1: Etiologies for osteonecrosis of femoral head $(\mathrm{ONFH})^{[1]}$.

\begin{tabular}{|c|c|c|c|}
\hline Direct & Associated factors & Pancreatitis \\
\hline Hip dislocation & Coagulation disorders & Hypercortisolism & Cushing's disease \\
\hline Femoral neck fracture & Alcoholism & Smoking & Endotoxin reactions \\
\hline Surgical exposure of the femoral neck & Hemophilia & Systemic lupus erythematosus & Serum sickness \\
\hline Radiation & Thrombophilia & Tolyarteritis & Hyperlipidemia/hyperlipoproteinemia \\
\hline caisson disease & Hypofibrinolysis & Hyperparathyroidism & Chemotherapy \\
\hline Sickle cell crisis & Genetic polymorphisms & Diabetes mellitus & Nephrotic syndrome \\
\hline & Chronic diseases & Chronic kidney disease & Hemoglobinopathies/thalassemia \\
\hline
\end{tabular}

Table 2: The 2001 revised criteria for diagnosis, classification, and staging of idiopathic osteonecrosis of the femoral head ${ }^{[5]}$.

\begin{tabular}{|c|c|c|}
\hline S. no & Criteria & Patient details \\
\hline 1 & $\begin{array}{c}\text { collapse of the femoral head (including crescent sign) without joint-space narrowing or acetabular abnormality } \\
\text { on x-ray images }\end{array}$ & No \\
\hline 2 & demarcating sclerosis in the femoral head without joint-space narrowing or acetabular abnormality & Yes \\
\hline 3 & "cold in hot" on bone scans & Not done \\
\hline 4 & low-intensity band on T1-weighted MRI (band like pattern); & Yes \\
\hline 5 & Trabecular and marrow necrosis on histology. & Yes \\
\hline
\end{tabular}

Diagnosed if two of these five criteria are present and does not have bone tumors or dysplasia.

Table 3: Ficat and Arlet classification of $\mathrm{ONFH}^{[4]}$.

\begin{tabular}{|c|c|c|c|c|}
\hline Stage & Symptoms & Radiography & Bone scan & Pathological Findings \\
\hline 0 & None & Normal & Decreased uptake & Infarct of weight bearing portion of head \\
\hline 1 & None/mild & Normal & Cold spot & Spontaneous repair \\
\hline 2A & Mild & Density + cyst, normal joint line and contour & Increased Uptake & \\
\hline 2B & Mild & Flattening(crescent sign) & Increased uptake & \\
\hline 3 & Moderate & Collapse, loss of contour of head & Increased uptake & Subchondral fracture and collapse \\
\hline 4 & Severe & Joint space narrowing, acetabular changes & Increased uptake & Osteoarthritic changes \\
\hline
\end{tabular}

\section{References}

1. LaPorte DM, Mont MA, Mohan V, Jones LC. Multifocal osteonecrosis. J Rheumatol. 1998; 25:1968-74.

2. Mont MA, Jones LC, Hungerford DS. Non-traumatic osteonecrosis of the femoral head: Ten years later- current concepts review. J Bone Joint Surg Am. 2006; 88:1107-29.

3. Assouline-Dayan Y, Chang C, Greenspan A. Pathogenesis and natural history of osteonecrosis. Semin Arthritis Rheum. 2002; 32(2):94-124.

4. Ficat RP. Idiopathic bone necrosis of the femoral head. Early diagnosis and treatment. J Bone Joint Surg Br. 1985; 67:3-9.

5. Sugano N, Atsumi T, Ohzono K. The 2001 revised criteria for diagnosis, classification, and staging of idiopathic osteonecrosis of the femoral head. J Orthop Sci. 2002; 7(5):601-5.

6. Steinberg ME, Hayken GD, Steinberg DR. A quantitative system for staging avascular necrosis. J Bone Joint Surg Br. 1995; 77:34-41.

7. ARCO (Association Research Circulation Osseous).
Committee on Terminology and Classification. ARCO News. 1992; 4:41-6.

8. Marcus ND, Enneking WF, Massam RF. The silent hip in ideopathic aseptic necrosis. Treatment by bone grafting. J Bone Joint Surg Am. 1973; 55:1351-66.

9. Ohzono K, Salto M, Sugano N. The fate of nontraumatic avascular necrosis of the femoral head. A radiologic classification to formulate prognosis. Clin Orthop. 1992; 277:73-8.

10. Sujit Kumar Tripathy, Tarun Goyal, Ramesh Kumar Sen. Management of femoral head osteonecrosis: Current concepts Indian J Orthop. 2015; 49(1):28-45. 